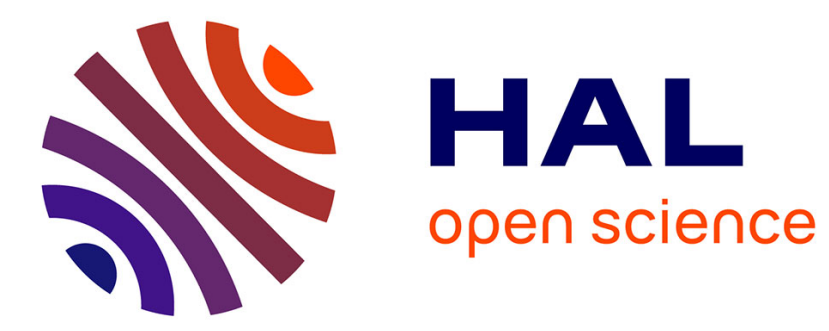

\title{
Preference for attractive faces is species-specific.
}

Fabrice Damon, Zhihan Li, Yin Yan, Wu Li, Kun Guo, Paul Quinn, Olivier Pascalis, David Meary

\section{To cite this version:}

Fabrice Damon, Zhihan Li, Yin Yan, Wu Li, Kun Guo, et al.. Preference for attractive faces is speciesspecific.. Journal of Comparative Psychology, 2019, 133 (2), pp.262-271. 10.1037/com0000148 . hal02348194

\section{HAL Id: hal-02348194 \\ https://hal.science/hal-02348194}

Submitted on 11 Oct 2021

HAL is a multi-disciplinary open access archive for the deposit and dissemination of scientific research documents, whether they are published or not. The documents may come from teaching and research institutions in France or abroad, or from public or private research centers.
L'archive ouverte pluridisciplinaire HAL, est destinée au dépôt et à la diffusion de documents scientifiques de niveau recherche, publiés ou non, émanant des établissements d'enseignement et de recherche français ou étrangers, des laboratoires publics ou privés. 


\title{
Preference for Attractive Faces Is Species-Specific
}

\author{
Fabrice Damon \\ Université Bourgogne Franche-Comté
}

Kun Guo
University of Lincoln

\author{
Zhihan Li, Yin Yan, and $\mathrm{Wu} \mathrm{Li}$ \\ Beijing Normal University
}

\author{
Paul C. Quinn \\ University of Delaware
}

\author{
Olivier Pascalis and David Méary \\ Université Grenoble Alpes and Centre National de la Recherche Scientifique, Grenoble, France
}

\begin{abstract}
Studies on facial attractiveness in human adults, infants, and newborns have consistently reported a visual preference for faces rated as attractive compared with faces rated as unattractive. Biological accounts of facial attractiveness have typically presented such preferences as arising from adaptations for mate choice or as by-products of general sensory bias. In this cross-species study, we examined whether explicit ratings of attractiveness made by human judges would predict implicit visual preferences in other humans and also in rhesus macaques and, if they do, whether such preferences would extend beyond conspecific faces. Results showed that human ratings of attractiveness can predict implicit preferences in nonhuman primates (macaque monkeys; Macaca mulatta). However, we also found a species-specific effect of face attractiveness in which humans showed a visual preference for human faces (but not macaque faces) rated as attractive, and macaques displayed a visual preference for macaque faces (but not human faces) rated as attractive. Overall, the findings suggest that attentional bias toward attractive faces arises neither from an exclusive operation of mate choice adaptation mechanisms nor from the sole influence of a general sensory bias, but rather reflects their interaction. The influence of a general sensory bias may be modulated by the categorization of a face as conspecific or heterospecific, leading to species-specific preference for attractive faces.
\end{abstract}

Keywords: humans, rhesus macaques, faces, attractiveness, eye-tracking, mate choice

Supplemental materials: http://dx.doi.org/10.1037/com0000148.supp

Despite the long held view that "beauty is in the eye of the beholder," judgments of facial attractiveness are largely shared both within and between cultures (Cunningham et al., 1995; Jones

This article was published Online First December 13, 2018.

Fabrice Damon, Centre des Sciences du Goût et de l'Alimentation, AgroSup Dijon, National Center For Scientific Research [CNRS], National Institute for Agricultural Research [INRA], Université Bourgogne Franche-Comté; Zhihan $\mathrm{Li}$, Yin Yan, and $\mathrm{Wu} \mathrm{Li}$, State Key Laboratory of Cognitive Neuroscience and Learning and IDG/McGovern Institute for Brain Research, Beijing Normal University; Kun Guo, School of Psychology, University of Lincoln; Paul C. Quinn, Department of Psychological and Brain Sciences, University of Delaware; Olivier Pascalis and David Méary, Université Grenoble Alpes, Laboratoire de Psychologie et Neurocognition, and Centre National de la Recherche Scientifique, Grenoble, France.

We thank Annika Paukner for sharing pictures of rhesus macaque faces, and Mike Burt for sharing pictures of human faces. This research was supported by the Open Research Fund of the State Key Laboratory of Cognitive Neuroscience and Learning, and the National Natural Science Foundation of China (Grant 91432102).

$\mathrm{R}$ code and raw data are available at: https://mfr.osf.io/render?url= https $\% 3 \mathrm{~A} \% 2 \mathrm{~F} \% 2 \mathrm{Fosf}$.io\%2Ftq 8 bg $\% 2$ Fdownload.

Correspondence concerning this article should be addressed to Fabrice Damon, Centre des Sciences du Goût et de l'Alimentation, INRA/CNRS, Université Bourgogne Franche-Comté, Bâtiment Centre des Sciences du Goût, 9 East Boulevard Jeanne d'Arc, 21000 Dijon. E-mail: damon.fabrice@gmail.com
\& Hill, 1993; Langlois et al., 2000; Little, Jones, \& DeBruine, 2011; Perrett et al., 1998; Perrett, May, \& Yoshikawa, 1994; Rhodes, 2006; Rhodes et al., 2001). While acknowledging interobserver variation (Hönekopp, 2006), multiple reports indicate that there can be a common sensibility of what is attractive across cultures and point to a biological account of the preference for attractive faces (Hahn \& Perrett, 2014; Little et al., 2011; Rhodes, 2006).

Facial attractiveness is influenced by a variety of factors (for a review and a meta-analysis, see Little et al., 2011; Rhodes, 2006), eluding explanation by a single principle. Due to this multifactor determination, physical measurements of attractiveness are not straightforward as are, for example, height or weight measures. The easiest and most common way to evaluate beauty in a face is to ask human observers to rate a face for its attractiveness. These explicit judgments of attractiveness are a good predictor of implicit behaviors linked to preferences, such as longer looking times, either in adults (Hayden, Parikh, Deaner, \& Platt, 2007; Leder, Tinio, Fuchs, \& Bohrn, 2010; Shimojo, Simion, Shimojo, \& Scheier, 2003), or in infants from 2- to 3-day-olds to 15-montholds (Damon, Méary, et al., 2017; Damon, Mottier, Méary, \& Pascalis, 2017; Langlois, Ritter, Roggman, \& Vaughn, 1991; Langlois et al., 1987; Samuels, Butterworth, Roberts, Graupner, \& Hole, 1994; Samuels \& Ewy, 1985; Slater, Quinn, Hayes, \& 
Brown, 2000; Slater et al., 1998; Van Duuren, Kendell-Scott, \& Stark, 2003). The overlap between ratings made by adults and visual preferences in adults and infants suggests that some of the features upon which adult raters rely to make their judgments are correlated with the features that drive visual attention toward implicit preferences. Contrary to adults, young infants are unlikely to be influenced by cultural standards of beauty. Thus, such results might also indicate that there are some biologically based principles of attractiveness (Damon, Mottier, et al., 2017; Quinn, Kelly, Lee, Pascalis, \& Slater, 2008; Rhodes, 2006).

Two evolutionary frameworks have been proposed to explain what makes faces attractive and why humans show preferences for attractive faces. On the one hand, preference for attractive faces can be seen as an adaptation to solve the problem of mate choice because attractiveness and its components may serve as indicators of mate quality, such as health, parasitic resistance, or fertility (Fink \& Penton-Voak, 2002; Little et al., 2011; Thornhill \& Gangestad, 1993, 1994; Thornhill \& Møller, 1997; Zebrowitz \& Rhodes, 2004). Potential mate quality indicators include, but are not limited to, prototypicality (i.e., the proximity of a face to the average of a population, in terms of mathematical trait values), sexual dimorphism (i.e., feminine traits in female faces and masculine traits in male faces), and bilateral symmetry (i.e., the similarity between left and right halves of the face). For example, averageness is linked with greater genetic diversity, which may result in greater parasitic resistance, whereas deviations from average could signal chromosomal disorders (Thornhill \& Møller, 1997). Similarly, facial symmetry can be an indicator of stability in development and resistance to environmental perturbations (Little et al., 2011; Thornhill \& Gangestad, 1994; Thornhill \& Møller, 1997).

On the other hand, preference for attractive faces could be an emergent property of our object recognition systems (Damon, Mottier, et al., 2017; Halberstadt, 2006; Halberstadt \& Rhodes, 2000, 2003; Quinn et al., 2008; Rhodes, 2006; Wallis, 2013). Generalization effects in biological systems of object recognition have been shown to induce biases toward prototypical or symmetrical stimuli as a response after category learning (Enquist \& Arak, 1994; Enquist \& Johnstone, 1997; Ghirlanda, Jansson, \& Enquist, 2002; Jansson, Forkman, \& Enquist, 2002; Wallis, 2013; Wallis, Siebeck, Swann, Blanz, \& Bülthoff, 2008). Even preferences for extreme sexual dimorphism can be attributed to sensory biases without a link to individual fitness (Garcia \& Ramirez, 2005; Guilford \& Dawkins, 1991; Ryan, 1998).

However, these frameworks are not mutually exclusive. Both mechanisms may act independently to shape attractiveness preference (Waitt \& Little, 2006), or one could derive from the other. For example, initial sensory biases could evolve as signals of mate quality (Garcia \& Ramirez, 2005; Rhodes, 2006), or mechanisms derived from mate choice could operate on top of perceptual biases to make humans particularly attentive to facial attractiveness in conspecifics (Little \& Jones, 2003). These possibilities seem, at first glance, to conflict with reports showing that components of attractiveness such as symmetry or prototypicality can influence preferences for a variety of stimuli, including those both relevant and not relevant to mate choice in humans (Halberstadt \& Rhodes, 2000, 2003; Reber, Schwarz, \& Winkielman, 2004) and monkeys (Anderson, Kuwahata, Kuroshima, Leighty, \& Fujita, 2005; Damon, Méary, et al., 2017; Waitt \& Little, 2006, but see Tomeo,
Ungerleider, \& Liu, 2017). However, the influence of these components has been shown to be modulated by the category of stimuli presented. Symmetry is most pleasant when it corresponds to human faces rather than to the faces of other species or nonface objects (Little, 2014). Similarly, the magnitude of the influence of prototypicality on attractiveness judgments for exemplars of various nonhuman animal categories is related to their perceived or actual phylogenetic similarity to humans (Halberstadt, 2006). From an evolutionary perspective, it would indeed make sense that humans are more sensitive to attractive traits in human faces compared with other-species faces.

Both the mate choice and the sensory bias frameworks place the mechanisms responsible for the preferences for attractive faces in the evolution of the human lineage (Little et al., 2011; Rhodes, 2006), leaving open the possibility that nonhuman primates might also share such mechanisms, for example, preference for symmetry or regularity in monkeys (Anderson et al., 2005; Waitt \& Little, 2006), and therefore show a form of sensitivity to attractive faces. Furthermore, if human ratings of attractiveness are the product of mechanisms shared among primates, they might also predict visual face preferences in monkeys. Although the issue of how much a monkey evaluates a face as attractive is a question difficult to address (if even possible), implicit face preferences can be inferred from looking-time measures (Méary, Li, Li, Guo, \& Pascalis, 2014).

The aim of the current study was to determine whether explicit ratings of attractiveness by human judges would predict implicit visual preferences in other humans and also in rhesus macaques and, if they do, whether such preferences would extend beyond conspecific faces. The sensory bias account of preference formation implies that human ratings of attractiveness should predict the visual preferences of human observers, irrespective of the species corresponding to the stimulus faces. Human ratings of attractiveness of human and monkey faces could also predict the visual preferences of macaque observers if the macaques share similar perceptual biases due to the common lineage between humans and macaques. By contrast, a mate choice account suggests that humans should present a preference for attractive human faces but not attractive monkey faces. Furthermore, if human ratings of attractiveness only reflect human mate choice, macaques should not present a preference for attractive human or attractive monkey faces. A last possibility is to envision that both mechanisms can play a role in preference formation but that their contributions are modulated by the species of the faces.

To test these hypotheses, human judges were asked to rate the attractiveness of human and rhesus macaque faces. The faces were then paired in accord with the attractiveness ratings (i.e., attractive faces were paired with unattractive faces) and shown to human and rhesus macaque participants while their eye-movements were recorded.

\section{Method}

\section{Participants}

Humans. A total of 26 students from the University of Grenoble Alpes (23-32 years, 13 women) participated in the experiment. Participants had no specific history of being familiar with rhesus monkey faces, although they all had seen monkey 
faces in TV documentaries or in books. Participation was rewarded with credit in an experimental psychology course. The investigation was conducted at the University of Grenoble Alpes, approved by the local ethics committee "Comité d'éthique des centre d'investigation clinique de l'inter-région Rhône-Alpes-Auvergne", Institutional Review Board, and informed consent was obtained.

Monkeys. Five male adult rhesus macaques (Macaca mulatta, 5-9 kg, 5-9 years) participated in the experiment. All the monkeys were born in captivity and housed indoors. They grew up in groups and were exposed to their conspecifics as well as masked and unmasked caretakers on a daily basis in Beijing, China. The monkeys had very limited experience with Caucasian faces, although they could have occasionally seen Caucasian visitors. The monkeys also had limited experience with viewing photographs of Caucasian and Asian human and monkey faces $(<1$ week for each tested monkey) and were unfamiliar with the rhesus macaque and human faces used as stimuli. All of the monkeys were midranked individuals in the hierarchy of the colony. All the monkeys that participated in the current study had previous experience with eye-tracking experiments. They were familiar with the setting and the eye-tracking apparatus. Ethical approval was granted by the Institutional Animal Care and Use Committee of Beijing Normal University, with all procedures in compliance with the National Institutes of Health Guide for the Care and Use of Laboratory Animals.

\section{Stimuli}

We used 16 Caucasian faces (eight female) and 16 rhesus (16 female) macaque faces to make up the set of face pairs used in the experiments. A total of 12 rhesus macaque faces came from a rhesus cohort in the Laboratory of Comparative Ethology, and four faces came from the PrimFace database (http://visiome.neuroinf .jp/primface). All the faces were frontal views with open eyes and neutral (mouth closed) expression (see Figure 1 for an illustration of the faces used in the experiment). Macaques were presented with opposite sex faces only. Presenting the face of an unfamiliar own-sex conspecific could signal the presence of an out-group individual (i.e., potential rival), thus creating a situation of increased vigilance resulting in longer looking time (Pfefferle, Kazem, Brockhausen, Ruiz-Lambides, \& Widdig, 2014; Schell, Rieck, Schell, Hammerschmidt, \& Fischer, 2011). In a visual-preference paradigm, this gaze behavior would be confounded with any face preference due to attractiveness. Because it is difficult to unequivocally establish the biological significance of specific response biases from looking-time procedures, we sought to avoid this potential confound. Unfamiliar opposite sex faces of conspecifics (portraying possible mates) do not trigger vigilance behavior and are better suited to our purpose. Studies examining the influence of various facial features on face preference in macaque monkeys have typically used opposite sex faces (Dubuc, Allen, Maestripieri, \& Higham, 2014; Hughes, Higham, Allen, Elliot, \& Hayden, 2015; Waitt et al., 2003; Waitt \& Little, 2006).

Attractiveness ratings. The 16 rhesus macaque faces were previously individually rated for attractiveness by a group of 15 students from the University of Grenoble Alpes and by six primatologists from the University of Strasbourg. There was a strong correlation between the mean rating of the students (nonexperts with macaques) and the mean rating of the primatologists (experts with macaques), $r(14)=0.86$, and interrater reliability was good

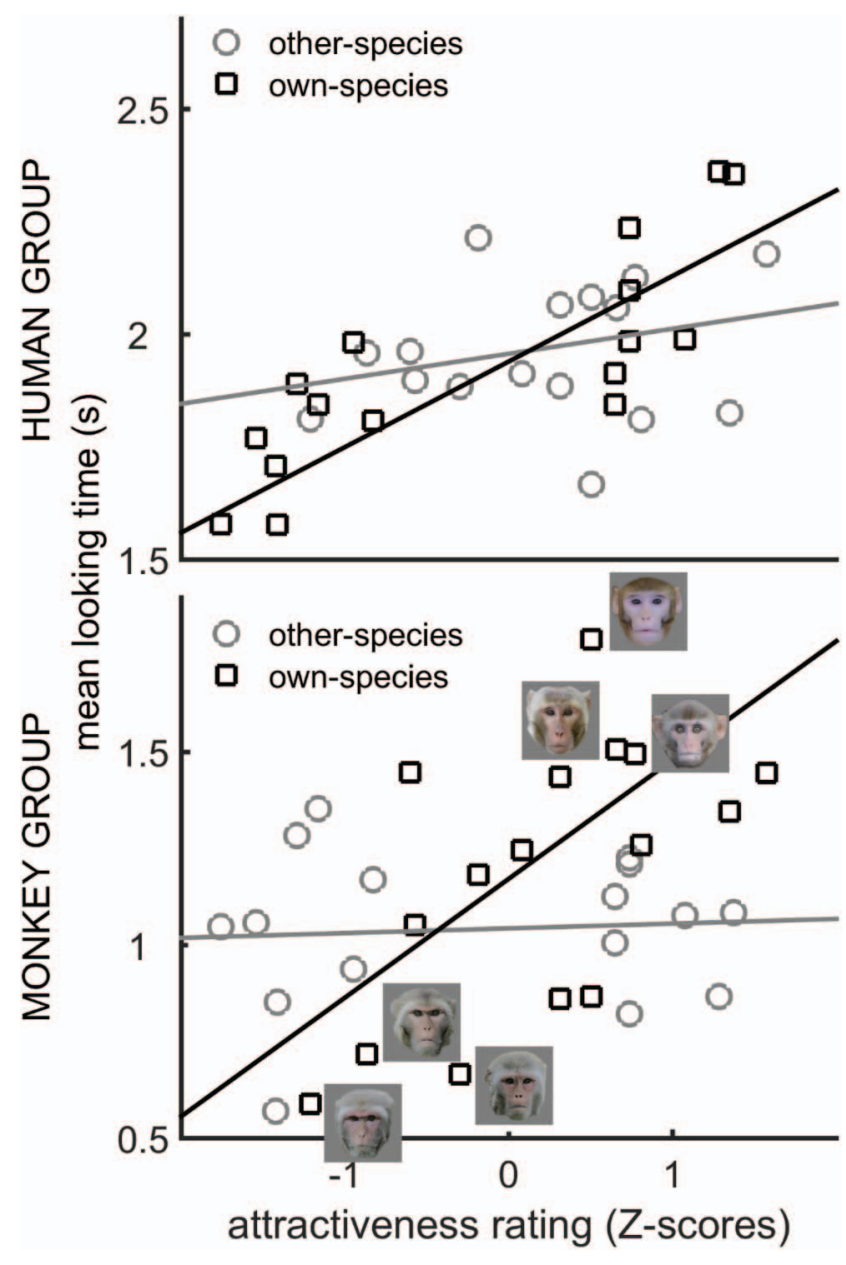

Figure 1. Mean looking time to faces with different attractiveness levels for the human (top) and rhesus macaque (bottom) groups. The effect of attractiveness is found only for own-species faces. The bottom plot also shows the photographs of the three rhesus macaque faces that were the least and most looked at by their conspecifics. See the online article for the color version of this figure.

(Cronbach's $\alpha=.76$ ), so all ratings were averaged together. The 16 human faces were rated by another group of 19 students. The faces were normalized for luminance in the $\mathrm{L}^{*} \mathrm{a}^{*} \mathrm{~b}$ color space before attractiveness evaluation. Attractiveness could range from 1 (low attractiveness) to 7 (high attractiveness). Attractiveness ratings of the monkey and human faces were normalized within their respective categories using $Z$ scores.

Visual preference task. Each attractive face was randomly paired with an unattractive face within species according to the attractiveness ratings. We prepared eight pairs of human faces (four pairs of male faces and four pairs of female faces) and eight pairs of rhesus faces (eight pairs of female faces), each showing faces with high and low attractiveness ratings. The faces were pasted side by side on a $30-\mathrm{cd} / \mathrm{m}^{2}$ gray background. We constructed a second set of 16 face pairs by counterbalancing the left-right positioning of the high and low attractiveness faces. Within an experimental session, the participants viewed each of the 16 face pairs twice, thus yielding a total of 32 stimulus pairs presented in a random order to each participant. 


\section{Procedure}

During the visual preference task, eye positions of monkey and human participants were measured by an EyeLink 1000 (SR Research Ltd., Ontario, Canada). For technical reasons, sampling frequency and viewing distance were $500 \mathrm{~Hz}$ and $100 \mathrm{~cm}$ for monkeys and $250 \mathrm{~Hz}$ and $60 \mathrm{~cm}$ for humans. A standard 5-point calibration procedure was conducted before the beginning of each experimental session. Both groups of participants viewed the display binocularly. Stimuli were displayed on a gamma-corrected color monitor (Iiyama Vision Master Pro 514, $40 \times 30 \mathrm{~cm}$, Iiyama, North America) with a resolution of $1024 \times 768$ pixels and frame rate of $100 \mathrm{~Hz}$. Given the screen distance and the face size, the stimuli on screen subtended visual angles of $12^{\circ}$ and $20^{\circ}$ vertically for the monkey and human participants, respectively.

Monkey participants. The detailed experimental setup has been described in (McFarland et al., 2013). The monkeys were seated in a primate chair with their head restrained. A trial was started with a fixation point (FP) displayed on the center of the monitor. If the monkeys maintained fixation for $1 \mathrm{~s}$, the FP disappeared, and one of the image pairs was presented for $5 \mathrm{~s}$. During the free-viewing presentation, the monkeys passively viewed the images. The intertrial interval was $1 \mathrm{~s}$, during which the monkeys received a juice reward without any specific task requirement related to the stimuli. We conducted three testing sessions for each monkey participant, separated by 2 to 3 days.

Human participants. Humans were also seated, and head movements were limited with a chin rest. A trial was started with an FP displayed on the center of the monitor. The experimenter triggered the image presentation manually after ensuring that the participant fixated on the FP. A drift correction was performed every five trials to realign gaze and correct for small involuntary head movement. Each stimulus pair was presented for $5 \mathrm{~s}$, and the instructions emphasized free viewing of the images. A single testing session included the 32 stimulus pairs presented in a random order.

\section{Results}

\section{Data Processing and Statistical Analysis}

All calculations for the identification of fixations were performed in degrees of visual angle. The parsing of the eye data into saccades and fixations was done according to the method developed by Engbert and Kliegl (2003) for microsaccades. Parameters were adjusted for saccade detection. In our analyses, the minimum duration for the fixations was set to $80 \mathrm{~ms}$. The fixations within each trial were then classified according to their locations (on the low or high attractiveness face, or elsewhere on the screen). Only trials where participants gazed at both faces, for at least one fixation and with the initial gaze on the FP, were included in the data set. In the group of human participants, these criteria excluded one and nine trials out of 416 trials (i.e., 0.2 and $2.16 \%$ of the trials) for the human and monkey face types, respectively. For the monkey participants, the number of valid trials for each monkey is given in Table 2 . The number of trials was 48 per face type $(3 \times$ 16). The number of valid trials was small for monkey I $(N=10$ and $N=12$ for the human and monkey faces, respectively), with 79 and $75 \%$ of invalid trials. For the other four rhesus macaques, the rejection rate ranged from $2 \%$ to $18 \%$.
The number of fixations and the total looking time on each face were calculated for each participant. The goal of the main analysis was to test whether the attractiveness level influenced looking time and whether this effect depended on face type (human or monkey). This was completed separately for the human and rhesus macaque groups using a linear model of the form $Y_{i j}=\mu+\alpha F_{i j}+\beta X_{i j}+$ $\gamma F_{i j} X_{i j}+E_{i j}$, where $Y_{i j}$ represented the group's looking duration at a face $j$ (one of the 16 faces used for each species) of face type $i$ (own or other-species), and $X_{i j}$ represented the $Z$ value of attractiveness for this face. Face type (human or rhesus macaque) was recoded as face species (own or other depending on the participant group) and was treated as a factor, with $F_{i j}=0$ for other-species faces and $F_{i j}=1$ for own-species faces. The $Z$ score of attractiveness was treated as a numeric variable. According to the linear model, $\mu$ is an intercept term that approximates the average looking time at other-species faces (due to the transformation of attractiveness ratings into $Z$ scores). The slope $\beta$ is a coefficient capturing the effect of attractiveness in other-species faces. The $\alpha$ and $\gamma$ terms represent the modification of the intercept and slope, respectively, when looking at own-species faces (i.e., when $F_{i j}=$ 1). We used partial $\eta_{p}^{2}$ measures to estimate effect sizes. Stimulus presentation and data processing were done with Matlab using the Psychtoolbox (Brainard, 1997), and the EyeLink Toolbox (Cornelissen, Peters, \& Palmer, 2002) for data acquisition. Statistical analyses were done with R (R Development Core Team, 2008).

\section{Linear Model of Attractiveness Effects}

Human participants. When applied to the mean spontaneous looking time in the human group, the linear model accounted for $49 \%$ of the variation in mean looking duration at the face photographs, multiple $R^{2}=0.49, F(3,28)=8.88, p<.001$. Table 1 reports the values for the model's parameter $\mu, \beta, \alpha$, and $\gamma$. Figure 1 (top) can be used to illustrate the model's output. The intercept coefficient $\mu$ and the slope coefficient $\beta$ were used to fit the looking duration for other-species faces. Because we used $Z$ scores for the attractiveness ratings, the intercept $\mu$ gives the mean looking time to other-species faces. The nonsignificant $t$ value for the slope $\beta$ indicates that mean

Table 1

Coefficients From the Linear Model and Corresponding $p$ Values (Coefficients are Time Values in Seconds)

\begin{tabular}{crrrrrr}
\hline Parameter & Estimate & $S E$ & $t$ value & $p$ value & $\eta_{p}^{2}$ & $\begin{array}{c}95 \% \text { confidence } \\
\text { interval }\end{array}$ \\
\hline \multicolumn{7}{c}{ Human group } \\
$\mu$ & 1.959 & .037 & 52.87 & $<.001$ & .990 & {$[1.88,2.03]$} \\
$\beta$ & 0.030 & .038 & 0.77 & .446 & .021 & {$[-0.05,0.11]$} \\
$\alpha$ & -0.025 & .052 & -0.48 & .638 & .008 & {$[-0.13,0.08]$} \\
$\gamma$ & 0.165 & .054 & 3.04 & $<.01$ & .249 & {$[0.05,0.28]$}
\end{tabular}

Residual standard error: 148 on 28 degrees of freedom

\begin{tabular}{lrrrrrr}
\hline \multicolumn{7}{c}{ Rhesus macaque group } \\
$\mu$ & 1.043 & .063 & 16.51 & $<.001$ & .907 & {$[0.91,1.17]$} \\
$\beta$ & 0.013 & .065 & 0.194 & .847 & .001 & {$[-0.12,0.15]$} \\
$\alpha$ & 0.139 & .089 & 1.553 & .132 & .079 & {$[-0.04,0.32]$} \\
$\gamma$ & 0.199 & .092 & 2.162 & $\mathbf{. 0 3 9}$ & .143 & {$[0.01,0.39]$}
\end{tabular}

Residual standard error: .253 on 28 degrees of freedom

Note. Bold face $=p<.05$. 
looking duration for other-species faces was not linearly related to attractiveness level.

The mean looking time to own-species faces was fitted using the intercept coefficient $(\mu+\alpha)$ and the slope $(\beta+\gamma)$. The change in mean looking time due to face type, captured by the coefficient $\alpha$, was not significant. This outcome suggests that, overall, both face types (own- and other-species faces) were looked at for the same average duration. However, the change in slope, captured by the coefficient $\gamma(\gamma=0.165 \mathrm{~s})$ was significant. This result indicates that attractiveness influenced the mean looking time to ownspecies faces. According to Table 1, the slope for the own-species faces was $0.194(\beta+\gamma)$, meaning that change of one unit in $\mathrm{Z}$ score was associated with an increase of $0.194 \mathrm{~s}$ in looking time. Thus, attractiveness ratings correlated with the spontaneous looking duration of human participants toward the faces of their conspecifics; however, this effect was not significant when the human participants looked at monkey faces.

Rhesus macaque participants. When applied to the mean spontaneous looking time in the group of rhesus macaque participants, the linear model accounted for $32 \%$ of the variation in mean looking duration at the face photographs, multiple $R^{2}=0.32, F(3,28)=4.34$, $p=.012$. The slope coefficient $\beta$ was nonsignificant, indicating that the mean looking time to other-species faces (i.e., the human faces in this case) was unrelated to the attractiveness ratings (Table 1). As for the human participants, the coefficient $\alpha$, representing the change in mean looking time between own-and other-species faces was not significant, suggesting that both face types (own- and other-species faces) were looked at for the same average duration. More importantly, the $\gamma$ coefficient was positive and significant, indicating an effect of attractiveness for own-species faces. Overall, then, as was the case for the human participants, attractiveness rating predicted the spontaneous looking duration of the rhesus macaque participants, but only for the faces of their conspecifics.

\section{Results From Individual Monkeys}

Table 2 provides the mean differences in number of fixations on human and monkey faces of high and low attractiveness for each rhesus macaque participant. When the monkeys were looking at pairs of human faces, neither the number of fixations nor the looking times increased significantly for faces of high attractiveness. For conspecific monkey faces of high versus low attractiveness, however, we found a significant increase in both fixation number and looking time toward faces high in attractiveness in three out of five monkeys. Monkey I had only a small number of valid trials but was nevertheless included in the study. Removing this monkey's data strengthened the ownspecies effect found in the previous analysis of monkey performance.

\section{Additional Analyses}

Effect of gender. An attractiveness preference influenced by mate choice mechanisms would imply that the effect of attractiveness is stronger for male participants looking at attractive female faces (compared with attractive male faces). Conversely, female participants should present a stronger effect of attractiveness for male than female faces.

To examine this possibility, we tested the influence of "Face Gender," "Subject Gender," and "Attractiveness Rating" on the human looking times toward attractive faces. Results showed interactions between Attractiveness Rating and Subject Gender, and between Attractiveness Rating and Face Gender-Rating $X$ Subject Gender, $F(1,832)=23.989, p<.001$; Rating $\times$ Face Gender, $F(1,832)=18.565, p<.001$, see Table S2, in online supplemental material. Overall, these interactions indicated that (a) the effect of attractiveness was stronger in our male participants looking at female faces, which is consistent with the mate choice hypothesis, and that (b) the effect of attractiveness was also stronger on female face stimuli than on male face stimuli. Although this latter result may reflect an artifact of our stimuli, it may also indicate that female participants attended to attractive female faces. Such behavior has been previously interpreted either as engagement of "social comparison" (e.g., check out the competition) or a higher tendency toward bisexual

Table 2

Mean Differences in the Number of Fixations (N Fix) and Looking Time (in Milliseconds) Between Faces of High and Low Attractiveness for Each Rhesus Macaque Participant and Stimulus Type (Human vs. Rhesus Macaque Faces)

\begin{tabular}{|c|c|c|c|c|c|c|c|c|c|}
\hline Monkey participant & $\begin{array}{c}N \text { valid } \\
\text { trials }\end{array}$ & $\begin{array}{l}\text { Mean differences } \\
\text { in number of } \\
\text { fixations }\end{array}$ & $t$ & $p$ & {$[95 \% \mathrm{CI}]$} & $\begin{array}{l}\text { Mean differences } \\
\text { in LT }\end{array}$ & $t$ & $p$ & {$[95 \% \mathrm{CI}]$} \\
\hline \multicolumn{10}{|c|}{ Human faces } \\
\hline $\mathrm{D}$ & 42 & 0 & 0 & .50 & {$[-1.26,1.26]$} & -34 & -.21 & .58 & {$[-370,302]$} \\
\hline $\mathrm{C}$ & 39 & -1.23 & -1.22 & .89 & {$[-3.26,0.80]$} & -298 & -1.22 & .88 & {$[-794,198]$} \\
\hline G & 40 & -.55 & -1.69 & .95 & {$[-1.21,0.11]$} & -133 & -1.53 & .93 & {$[-309,43]$} \\
\hline I & 10 & .7 & .94 & .18 & {$[-.98,2.38]$} & 291 & .84 & .21 & {$[-489,1071]$} \\
\hline $\mathrm{J}$ & 47 & 1 & 1.15 & .13 & {$[-.76,2.76]$} & 344 & 1.06 & .15 & {$[-311,999]$} \\
\hline \multicolumn{10}{|c|}{ Rhesus macaque faces } \\
\hline D & 46 & .68 & 1.46 & .07 & {$[-.24,1.60]$} & 149 & 1.06 & .14 & {$[-133,431]$} \\
\hline $\mathrm{C}$ & 44 & 1.41 & 2.21 & .02 & {$[0.13,2.69]$} & 435 & 2.51 & $<.01$ & {$[86,784]$} \\
\hline G & 43 & 1.56 & 2.75 & $<.01$ & {$[0.42,2.70]$} & 361 & 2.63 & $<.01$ & {$[85,637]$} \\
\hline I & 12 & -.67 & -1.17 & .86 & {$[-1.92,0.58]$} & -296 & -1.31 & .89 & {$[-790,198]$} \\
\hline $\mathrm{J}$ & 45 & 3.91 & 3.90 & $<.01$ & {$[1.89,5.93]$} & 1374 & 4.75 & $<.01$ & {$[792,1956]$} \\
\hline
\end{tabular}

Note. $\quad$ LT $=$ looking time; $\mathrm{CI}=$ confidence interval. Bold face $=p<.05$. 
orientation in female participants (Hall, Hogue, \& Guo, 2011, 2014).

We also examined the effect of Subject Gender on the human looking times toward monkey faces. This analysis showed no effect of Subject Gender, $F(1,828)=0.913, p=.340$, which is not surprising given that there was no effect of the attractiveness ratings on the human looking times toward monkey faces.

Our monkey participants were all males, and they were presented with female monkey faces, and with male and female human faces. We therefore examined the effect of Face Gender only for human faces. Results showed no effect of Face Gender or Rating, nor of any interaction (all $p \mathrm{~s}<.11$, see Table S3, in online supplemental material), indicating that there was no significant difference in monkey looking times on male versus female human faces.

Pearson correlation between looking times across species of observers. To examine the potential correlation between looking time across species of observers, we computed the Pearson's linear correlation coefficients between human and monkey looking times toward human faces, monkey faces, or both (Figure 1). Overall, we found no significant correlation for (a) looking times of humans and monkeys on human faces: $r(14)=0.17, p=.510,95 \% \mathrm{CI}$ $[-0.49,0.71]$, or (b) looking times of humans and monkeys on both human and monkey faces: $r(30)=0.29, p=.110,95 \% \mathrm{CI}$ $[-0.18,0.65]$. Only the correlation between human and monkey looking times on monkey faces approached significance, $r(14)=$ $0.44, p=.084,95 \%$ CI $[-0.23,0.83]$. These results are consistent with our pattern of findings showing that the attractiveness effect is species-specific (e.g., human and monkey looking times toward human faces were not correlated because only human participants looked longer at human faces rated as attractive). Notably, the correlation between human and monkey looking times on monkey faces is close to significance (although it is below the threshold of $\alpha=.05$ using a one-tailed $t$ test). Because monkey faces were rated by human judges for attractiveness, it follows that human looking times would show a trend toward a preference for the monkey faces rated as attractive. The effect size is however much smaller for monkey faces $\left(R^{2}=0.11\right)$ compared with human faces $\left(R^{2}=0.66\right)$, supporting our conclusion that the influence of attractiveness on looking times is stronger for own-species faces than for other-species faces. Further analyses, including (a) representation of the time course of visual attention toward high and low attractiveness faces; (b) the spatial distribution of fixations over the human and monkey faces; (c) scatter plots of human and monkey looking times toward human faces, monkey faces, or both; and (d) analysis of variance tables describing overall effects of each factor (main effect and interaction) for all the models tested, are provided in the supplemental files.

\section{Discussion}

In the present study, we sought to examine whether explicit evaluations of facial attractiveness by human judges would predict implicit visual preferences of adult humans and rhesus macaques. The findings revealed species-specific visual preferences for faces with high attractiveness ratings, because human participants looked longer at attractive human faces but not attractive monkey faces, whereas macaque participants looked longer at attractive macaque faces but not attractive human faces. Strikingly, human judgments of facial attractiveness of monkey faces predicted the visual preferences of macaque monkeys, suggesting at least a partial overlap between the features used by the human raters and those driving visual attention in macaques.

The current outcomes can be discussed in the context of the larger debate about the origin of preferences for attractive faces. Do attractiveness preferences reflect an adaptation for mate choice, or do they come about as a consequence of sensory processing biases (Halberstadt, 2006; Halberstadt \& Rhodes, 2000, 2003; Rhodes, 2006)? Our view is that the findings can be taken as evidence that both explanations are needed to account for attractiveness judgments and should not be considered as mutually exclusive alternatives. Although preferences stemming from adaptation for mate choice are likely to be species-specific (Halberstadt, 2006; Little, 2014), preferences arising out of general perceptual mechanisms could be shared among phylogenetically close species, such as humans and macaques, and have led to similar preferences: for symmetry in humans, capuchin monkeys, and squirrel monkeys (Anderson et al., 2005; Little, 2014), for curved contours in humans and chimpanzees (Munar, Gómez-Puerto, Call, \& Nadal, 2015), and for prototypicality in human and macaque infants (Damon, Méary, et al., 2017).

The human looking time preference for attractive human faces replicates previous findings (Hayden et al., 2007; Leder et al., 2010; Shimojo et al., 2003) and suggests that the features used by the independent group of observers to explicitly rate human faces were at least partly correlated with the features driving implicit visual attention in our group of human participants. Contrary to what was expected under a strict sensory bias account of preference formation, the attractiveness effect was not found for nonhuman primate faces. Human ratings of attractiveness predicted implicit preferences in humans only for own-species faces. This result is consistent with findings showing that some components of attractiveness such as symmetry (Little, 2014) or prototypicality (Halberstadt, 2006) have a greater influence on attractiveness judgments applied to human faces compared with other-species faces. When human observers rate the attractiveness of monkey faces, they may rely more on features linked to general perceptual mechanisms rather than features linked to adaptation to mate choice, which are irrelevant in this instance. In contrast, when human observers rate the attractiveness of human faces, influences of both basic perceptual mechanisms and features reflecting sexual selection pressures might contribute to responding. Features linked to human mate choice are likely to be irrelevant for macaques and, consequently, did not drive their visual attention for attractive human faces as they did for human participants. Yet, human judgments of facial attractiveness of monkey faces predicted the visual preferences of macaques. This outcome suggests that some of the features used by humans to rate the faces overlap with those driving visual attention in macaques. Features linked to general perceptual mechanisms are plausible candidates, as they may be shared between human and nonhuman primates. Moreover, it has been shown that both humans and monkeys find symmetry attractive in faces (Little et al., 2008; Waitt \& Little, 2006). Similarly, both human and macaque infants show visual preferences for face prototypicality (Damon, Méary, et al., 2017). Interestingly, the influence of symmetry or prototypicality on attractiveness preference appears to be stronger for frequently experienced faces (Damon, Méary, et al., 2017; Halberstadt, 2006; Little, 2014), which 
usually correspond to conspecific faces in ecological conditions. Along with the current findings, these results are consistent with a species-specific effect of face attractiveness.

However, it can be argued that the interaction between species and attractiveness could be due to a rating bias rather than a sensory bias in the participants. We believe that far from being mutually exclusive, both phenomena are linked. It may be because different mechanisms were at work when rating conspecific and heterospecific faces that the ratings of macaque faces were able to predict looking time in macaque participants, while ratings of human faces did not. We argue that the ratings of human faces may be perturbed by mate-quality influence, whereas ratings of macaque faces were solely influenced by more general sensory processes. Therefore, in a way, the species and attractiveness interaction may have reflected a rating bias, but the bias in turn reflected the influence of different mechanisms, that is, mate choice adaptation mechanisms, general sensory bias, and categorization of a face as a conspecific.

Despite the correlation between human ratings of attractiveness and monkey looking times, we acknowledge that it is difficult to unequivocally establish that visual preferences truly reflect stimulus attractiveness. However, there is considerable evidence that this can be considered a reasonable conclusion based on the data and has been interpreted as such in previous studies with human adults and infants, and nonhuman primates (Langlois et al., 1987; Leder et al., 2010; Quinn et al., 2008; Shimojo et al., 2003; Waitt \& Little, 2006). Visual preference paradigms typically bear such an uncertainty in interpretation because the preference is implicit and based on an inference. We do not suggest that there is a total overlap between the features that drive monkey looking times and those used by human raters. A more circumspect explanation would be to consider that there is a partial overlap of the features driving human ratings and gaze behavior in monkeys.

Humphrey (1972) suggested that two independent factors influence visual preferences in human and nonhuman primates, interest (stemming from stimulus information properties), and pleasure (stemming from attractiveness of the stimulus which induces pleasurable feelings). Of the two, interest is proposed to supersede pleasure in driving gaze behavior, with monkeys attending preferentially to stimuli with high information content despite their unpleasant properties. It is worth noting, however, that interest and pleasure are not mutually exclusive, and a stimulus can be both informative and attractive. In the current design, the use of opposite-sex faces of conspecifics reduced the probability of monkey faces triggering a vigilance response (Pfefferle et al., 2014; Schell et al., 2011) or aversion mechanisms (Mendelson, Haith, \& Goldman-Rakic, 1982; Taubert, Wardle, Flessert, Leopold, \& Ungerleider, 2017). The downside of this methodological choice is that the monkeys were only tested with female monkey faces, and thus our conclusions about monkey performance only apply for opposite sex faces. Similarly, because our monkey sample was exclusively composed of male macaques, our results might not generalize to female monkeys. Sex differences in the influence of facial features on visual preferences for faces are not uncommon (e.g., skin color, Dubuc et al., 2014; Waitt, Gerald, Little, \& Kraiselburd, 2006, or symmetry, Waitt \& Little, 2006). Hence, future studies could resolve this issue by examining attractiveness preferences in female macaque monkeys.
The findings also showed an unexpected dissociation between explicit judgments (i.e., attractiveness ratings by humans for humans and macaques) and attentional biases (i.e., preference by humans only for human faces and not for macaque faces). Although facial attractiveness ratings can be collected from adult human observers for almost any class of faces, not just for human faces, the implicit behavior that may be induced by a face rated as attractive (i.e., visual preference) could be tied to the evolutionary relevance of such a face, regardless of the origin of the preference (i.e., mate choice, sensory bias, or both mechanisms). The dissociation may indicate that implicit visual preferences are influenced by another cognitive process: categorization of a face as a conspecific. If so, triggering attractiveness-based visual preferences might necessitate prior categorization of a face as own-species. Human adults (Méary et al., 2014) and infants (Di Giorgio, Méary, Pascalis, \& Simion, 2013; Heron-Delaney, Wirth, \& Pascalis, 2011) preferentially allocate visual attention toward own-species faces over other-species faces, and similar findings have been reported in nonhuman primates (Fujita, 1987; Sugita, 2008, but see Méary et al., 2014). Moreover, other face processing tasks also reflect an attentional advantage for own-species faces, such as detection (e.g., in humans, Crouzet, Kirchner, \& Thorpe, 2010) and visual search (e.g., in humans, Simpson, Husband, Yee, Fullerton, \& Jakobsen, 2014; in macaques, Simpson et al., 2017).

Furthermore, both human and nonhuman adults have a faceprocessing system that becomes species-specific during early development, leading to poorer discrimination and recognition abilities in human infants for other-species faces as measured in looking-time tasks relying on familiarity or novelty preference (Pascalis \& Bachevalier, 1998; Pascalis, de Haan, \& Nelson, 2002). Human and nonhuman face processing systems become attuned to frequently experienced categories (e.g., human faces for humans, monkey faces for macaques) in relation to their perceptual experience with faces (Pascalis et al., 2005; Sugita, 2008). Of interest here is that this specialization in the recognition system might also alter the attractiveness system, weakening the effect of attractiveness for other-species faces. Thus, when human observers are asked to rate the attractiveness of monkey faces, they might not be able to recruit the "expert" face processing strategy that is used for human face processing (which may be human-specific) and hence rely more on general object processing strategies (which could be shared among primates). Note that such an interpretation leads to the prediction that infants tested before the perceptual narrowing window (i.e., 3- to 6-month-old infants, Maurer \& Werker, 2014) might show a preference for attractive other-species faces, whereas older infants (e.g., 9- to 12-month-old infants) should perform like the adult participants from the present study and display no such visual preference. Evidence consistent with this prediction includes the finding that 3- to 4-month-old human infants look longer at attractive over unattractive domestic and wild cat faces (Quinn et al., 2008); however, older infants have thus far not been tested for their preference for attractive versus unattractive other-species faces.

In conclusion, we have reported behavioral evidence of a species-specific effect of facial attractiveness in adult humans and macaques. For both species, attractive own-species faces (as rated by human observers), but not attractive other-species faces, were preferred. These findings suggest that (a) human ratings of attractiveness correlate with features driving visual attention in mon- 
keys, and (b) that implicit preferences for faces, even rated as attractive, are tied to their evolutionary relevance. To further evaluate the influence of face-processing specialization on face preferences, future investigations should examine the developmental trajectory of attractiveness preferences for own-or other-species faces, before and after the perceptual narrowing window.

\section{References}

Anderson, J. R., Kuwahata, H., Kuroshima, H., Leighty, K. A., \& Fujita, K. (2005). Are monkeys aesthetists? Rensch (1957) revisited. Journal of Experimental Psychology: Animal Behavior Processes, 31, 71-78. http://dx.doi.org/10.1037/0097-7403.31.1.71

Brainard, D. H. (1997). The psychophysics toolbox. Spatial Vision, 10, 433-436. http://dx.doi.org/10.1163/156856897X00357

Cornelissen, F. W., Peters, E. M., \& Palmer, J. (2002). The eyelink toolbox: Eye tracking with MATLAB and the Psychophysics Toolbox. Behavior Research Methods, Instruments, and Computers, 34, 613-617. http://dx.doi.org/10.3758/BF03195489

Crouzet, S. M., Kirchner, H., \& Thorpe, S. J. (2010). Fast saccades toward faces: Face detection in just $100 \mathrm{~ms}$. Journal of Vision, 10, 1-17. http://dx.doi.org/10.1167/10.4.16

Cunningham, M. R., Roberts, A. R., Barbee, A. P., Druen, P. B., \& Wu, C.-H. (1995). "Their ideas of beauty are, on the whole, the same as ours": Consistency and variability in the cross-cultural perception of female physical attractiveness. Journal of Personality and Social Psychology, 68, 261-279. http://dx.doi.org/10.1037/0022-3514.68.2.261

Damon, F., Méary, D., Quinn, P. C., Lee, K., Simpson, E. A., Paukner, A., . . Pascalis, O. (2017). Preference for facial averageness: Evidence for a common mechanism in human and macaque infants. Scientific Reports, 7, 46303. http://dx.doi.org/10.1038/srep46303

Damon, F., Mottier, H., Méary, D., \& Pascalis, O. (2017). A review of attractiveness preferences in infancy: From faces to objects. Adaptive Human Behavior and Physiology, 3, 321-336. http://dx.doi.org/10.1007/ s40750-017-0071-2

Di Giorgio, E., Méary, D., Pascalis, O., \& Simion, F. (2013). The face perception system becomes species-specific at 3 months: An eyetracking study. International Journal of Behavioral Development, 37, 95-99. http://dx.doi.org/10.1177/0165025412465362

Dubuc, C., Allen, W. L., Maestripieri, D., \& Higham, J. P. (2014). Is male rhesus macaque red color ornamentation attractive to females? Behavioral Ecology and Sociobiology, 68, 1215-1224. http://dx.doi.org/10 .1007/s00265-014-1732-9

Engbert, R., \& Kliegl, R. (2003). Microsaccades uncover the orientation of covert attention. Vision Research, 43, 1035-1045. http://dx.doi.org/10 .1016/S0042-6989(03)00084-1

Enquist, M., \& Arak, A. (1994). Symmetry, beauty and evolution. Nature, 372, 169-172. http://dx.doi.org/10.1038/372169a0

Enquist, M., \& Johnstone, R. A. (1997). Generalization and the evolution of symmetry preferences. Proceedings Biological Sciences, 264, 13451348. http://dx.doi.org/10.1098/rspb.1997.0186

Fink, B., \& Penton-Voak, I. (2002). Evolutionary psychology of facial attractiveness. Current Directions in Psychological Science, 11, 154158. http://dx.doi.org/10.1111/1467-8721.00190

Fujita, K. (1987). Species recognition by five macaque monkeys. Primates, 28, 353-366. http://dx.doi.org/10.1007/BF02381018

Garcia, C. M., \& Ramirez, E. (2005). Evidence that sensory traps can evolve into honest signals. Nature, 434, 501-505. http://dx.doi.org/10 .1038 /nature 03363

Ghirlanda, S., Jansson, L., \& Enquist, M. (2002). Chickens prefer beautiful humans. Human Nature, 13, 383-389. http://dx.doi.org/10.1007/s12110002-1021-6
Guilford, T., \& Dawkins, M. S. (1991). Receiver psychology and the evolution of animal signals. Animal Behaviour, 42, 1-14. http://dx.doi .org/10.1016/S0003-3472(05)80600-1

Hahn, A. C., \& Perrett, D. I. (2014). Neural and behavioral responses to attractiveness in adult and infant faces. Neuroscience and Biobehavioral Reviews, 46, 591-603. http://dx.doi.org/10.1016/j.neubiorev.2014.08.015

Halberstadt, J. (2006). The generality and ultimate origins of the attractiveness of prototypes. Personality and Social Psychology Review, 10, 166-183. http://dx.doi.org/10.1207/s15327957pspr1002_5

Halberstadt, J., \& Rhodes, G. (2000). The attractiveness of nonface averages: Implications for an evolutionary explanation of the attractiveness of average faces. Psychological Science, 11, 285-289. http://dx.doi.org/ $10.1111 / 1467-9280.00257$

Halberstadt, J., \& Rhodes, G. (2003). It's not just average faces that are attractive: Computer-manipulated averageness makes birds, fish, and automobiles attractive. Psychonomic Bulletin and Review, 10, 149-156. http://dx.doi.org/10.3758/BF03196479

Hall, C., Hogue, T., \& Guo, K. (2011). Differential gaze behavior towards sexually preferred and non-preferred human figures. Journal of Sex Research, 48, 461-469. http://dx.doi.org/10.1080/00224499.2010.521899

Hall, C. L., Hogue, T., \& Guo, K. (2014). Sexual cognition guides viewing strategies to human figures. Journal of Sex Research, 51, 184-196. http://dx.doi.org/10.1080/00224499.2012.716872

Hayden, B. Y., Parikh, P. C., Deaner, R. O., \& Platt, M. L. (2007). Economic principles motivating social attention in humans. Proceedings Biological Sciences, 274, 1751-1756. http://dx.doi.org/10.1098/rspb.2007.0368

Heron-Delaney, M., Wirth, S., \& Pascalis, O. (2011). Infants' knowledge of their own species. Philosophical Transactions of the Royal Society of London Series B, Biological Sciences, 366, 1753-1763. http://dx.doi .org/10.1098/rstb.2010.0371

Hönekopp, J. (2006). Once more: Is beauty in the eye of the beholder? Relative contributions of private and shared taste to judgments of facial attractiveness. Journal of Experimental Psychology: Human Perception and Performance, 32, 199-209. http://dx.doi.org/10.1037/0096-1523.32 .2 .199

Hughes, K. D., Higham, J. P., Allen, W. L., Elliot, A. J., \& Hayden, B. Y. (2015). Extraneous color affects female macaques' gaze preference for photographs of male conspecifics. Evolution and Human Behavior, 36 25-31. http://dx.doi.org/10.1016/j.evolhumbehav.2014.08.003

Humphrey, N. K. (1972). 'Interest' and 'Pleasure': Two determinants of a monkey's visual preferences. Perception, 1, 395-416.

Jansson, L., Forkman, R. N., \& Enquist, M. (2002). Experimental evidence of receiver bias for symmetry. Animal Behaviour, 63, 617-621. http:// dx.doi.org/10.1006/anbe.2001.1936

Jones, D., \& Hill, K. (1993). Criteria of facial attractiveness in five populations. Human Nature, 4, 271-296. http://dx.doi.org/10.1007/BF02692202

Langlois, J. H., Kalakanis, L., Rubenstein, A. J., Larson, A., Hallam, M., \& Smoot, M. (2000). Maxims or myths of beauty? A meta-analytic and theoretical review. Psychological Bulletin, 126, 390-423. http://dx.doi .org/10.1037/0033-2909.126.3.390

Langlois, J. H., Ritter, J. J. M., Roggman, L. A., \& Vaughn, L. S. (1991). Facial diversity and infant preferences for attractive faces. Developmental Psychology, 27, 79-84. http://dx.doi.org/10.1037/0012-1649.27.1.79

Langlois, J. H., Roggman, L. A., Casey, R. J., Ritter, J. M., Rieser-Danner, L. A., \& Jenkins, V. Y. (1987). Infant preferences for attractive faces: Rudiments of a stereotype? Developmental Psychology, 23, 363-369. http://dx.doi.org/10.1037/0012-1649.23.3.363

Leder, H., Tinio, P. P. L., Fuchs, I. M., \& Bohrn, I. (2010). When attractiveness demands longer looks: The effects of situation and gender. Quarterly Journal of Experimental Psychology, 63, 1858-1871. http:// dx.doi.org/10.1080/17470211003605142

Little, A. C. (2014). Domain specificity in human symmetry preferences: Symmetry is most pleasant when looking at human faces. Symmetry, 6 , 222-233. http://dx.doi.org/10.3390/sym6020222 
Little, A. C., \& Jones, B. C. (2003). Evidence against perceptual bias views for symmetry preferences in human faces. Proceedings Biological Sciences, 270, 1759-1763. http://dx.doi.org/10.1098/rspb.2003.2445

Little, A. C., Jones, B. C., \& DeBruine, L. M. (2011). Facial attractiveness: Evolutionary based research. Philosophical Transactions of the Royal Society of London Series B, Biological Sciences, 366, 1638-1659. http://dx.doi.org/10.1098/rstb.2010.0404

Little, A. C., Jones, B. C., Waitt, C., Tiddeman, B. P., Feinberg, D. R., Perrett, D. I., . . Marlowe, F. W. (2008). Symmetry is related to sexual dimorphism in faces: Data across culture and species. PLOS ONE, 3, e2106. http://dx.doi.org/10.1371/journal.pone.0002106

Maurer, D., \& Werker, J. F. (2014). Perceptual narrowing during infancy: A comparison of language and faces. Developmental Psychobiology, 56, 154-178. http://dx.doi.org/10.1002/dev.21177

McFarland, R., Roebuck, H., Yan, Y., Majolo, B., Li, W., \& Guo, K. (2013). Social interactions through the eyes of macaques and humans. PloS ONE, 8, 1-11. http://dx.doi.org/10.1371/journal.pone.0056437

Méary, D., Li, Z., Li, W., Guo, K., \& Pascalis, O. (2014). Seeing two faces together: Preference formation in humans and rhesus macaques. Animal Cognition, 17, 1107-1119. http://dx.doi.org/10.1007/s10071-014-0742-3

Mendelson, M. J., Haith, M. M., \& Goldman-Rakic, P. S. (1982). Face scanning and responsiveness to social cues in infant rhesus monkeys. Developmental Psychology, 18, 222-228. http://dx.doi.org/10.1037/00121649.18.2.222

Munar, E., Gómez-Puerto, G., Call, J., \& Nadal, M. (2015). Common visual preference for curved contours in humans and great apes. PLoS ONE, 10, e0141106. http://dx.doi.org/10.1371/journal.pone.0141106

Pascalis, O., \& Bachevalier, J. (1998). Face recognition in primates: A cross-species study. Behavioural Processes, 43, 87-96. http://dx.doi.org/ 10.1016/S0376-6357(97)00090-9

Pascalis, O., de Haan, M., \& Nelson, C. A. (2002). Is face processing species-specific during the first year of life? Science, 296, 1321-1323. http://dx.doi.org/10.1126/science.1070223

Pascalis, O., Scott, L. S., Kelly, D. J., Shannon, R. W., Nicholson, E., Coleman, M., \& Nelson, C. A. (2005). Plasticity of face processing in infancy. Proceedings of the National Academy of Sciences of the United States of America, 102, 5297-5300. http://dx.doi.org/10.1073/pnas .0406627102

Perrett, D. I., Lee, K. J., Penton-Voak, I., Rowland, D., Yoshikawa, S., Burt, D. M., . . Akamatsu, S. (1998). Effects of sexual dimorphism on facial attractiveness. Nature, 394, 884-887. http://dx.doi.org/10.1038/ 29772

Perrett, D. I., May, K. A., \& Yoshikawa, S. (1994). Facial shape and judgements of female attractiveness. Nature, 368, 239-242. http://dx.doi .org/10.1038/368239a0

Pfefferle, D., Kazem, A. J. N., Brockhausen, R. R., Ruiz-Lambides, A. V., $\&$ Widdig, A. (2014). Monkeys spontaneously discriminate their unfamiliar paternal kin under natural conditions using facial cues. Current Biology, 24, 1806-1810. http://dx.doi.org/10.1016/j.cub.2014.06.058

Quinn, P. C., Kelly, D. J., Lee, K., Pascalis, O., \& Slater, A. M. (2008). Preference for attractive faces in human infants extends beyond conspecifics. Developmental Science, 11, 76-83. http://dx.doi.org/ 10.1111/j.1467-7687.2007.00647.x

R Development Core Team. (2008). R: A language and environment for statistical computing. Vienna, Austria: R Foundation for Statistical Computing. Retrieved from http://www.r-project.org

Reber, R., Schwarz, N., \& Winkielman, P. (2004). Processing fluency and aesthetic pleasure: Is beauty in the perceiver's processing experience? Personality and Social Psychology Review, 8, 364-382. http://dx.doi .org/10.1207/s15327957pspr0804_3

Rhodes, G. (2006). The evolutionary psychology of facial beauty. Annual Review of Psychology, 57, 199-226. http://dx.doi.org/10.1146/annurev .psych.57.102904.190208
Rhodes, G., Yoshikawa, S., Clark, A., Lee, K., McKay, R., \& Akamatsu, S. (2001). Attractiveness of facial averageness and symmetry in nonwestern cultures: In search of biologically based standards of beauty. Perception, 30, 611-625. http://dx.doi.org/10.1068/p3123

Ryan, M. J. (1998). Sexual selection, receiver biases, and the evolution of sex differences. Science, 281, 1999-2003. http://dx.doi.org/10.1126/science .281.5385.1999

Samuels, C. A., Butterworth, G., Roberts, T., Graupner, L., \& Hole, G. (1994). Facial aesthetics: Babies prefer attractiveness to symmetry. Perception, 23, 823-831. http://dx.doi.org/10.1068/p230823

Samuels, C. A., \& Ewy, R. (1985). Aesthetic perception of faces during infancy. British Journal of Developmental Psychology, 3, 221-228. http://dx.doi.org/10.1111/j.2044-835X.1985.tb00975.x

Schell, A., Rieck, K., Schell, K., Hammerschmidt, K., \& Fischer, J. (2011). Adult but not juvenile Barbary macaques spontaneously recognize group members from pictures. Animal Cognition, 14, $503-$ 509. http://dx.doi.org/10.1007/s10071-011-0383-8

Shimojo, S., Simion, C., Shimojo, E., \& Scheier, C. (2003). Gaze bias both reflects and influences preference. Nature Neuroscience, 6, 1317-1322. http://dx.doi.org/10.1038/nn1150

Simpson, E. A., Husband, H. L., Yee, K., Fullerton, A., \& Jakobsen, K. V. (2014). Visual search efficiency is greater for human faces compared to animal faces. Experimental Psychology, 61, 439-456. http://dx.doi.org/ 10.1027/1618-3169/a000263

Simpson, E. A., Jakobsen, K. V., Damon, F., Suomi, S. J., Ferrari, P. F., \& Paukner, A. (2017). Face detection and the development of own-species bias in infant macaques. Child Development, 88, 103-113. http://dx.doi .org/10.1111/cdev.12565

Slater, A. M., Quinn, P. C., Hayes, R., \& Brown, E. (2000). The role of facial orientation in newborn infants' preference for attractive faces. Developmental Science, 3, 181-185. http://dx.doi.org/10.1111/1467-7687.00111

Slater, A. M., Von der Schulenburg, C., Brown, E., Badenoch, M., Butterworth, G., Parsons, S., \& Samuels, C. A. (1998). Newborn infants prefer attractive faces. Infant Behavior and Development, 21, 345-354. http://dx.doi.org/10.1016/S0163-6383(98)90011-X

Sugita, Y. (2008). Face perception in monkeys reared with no exposure to faces. Proceedings of the National Academy of Sciences of the United States of America, 105, 394-398. http://dx.doi.org/10.1073/pnas.0706079105

Taubert, J., Wardle, S. G., Flessert, M., Leopold, D. A., \& Ungerleider, L. G. (2017). Face pareidolia in the rhesus monkey. Current Biology, 27, 2505-2509.e2. http://dx.doi.org/10.1016/j.cub.2017.06.075

Thornhill, R., \& Gangestad, S. W. (1993). Human facial beauty: Averageness, symmetry, and parasite resistance. Human Nature, 4, 237-269. http://dx.doi.org/10.1007/BF02692201

Thornhill, R., \& Gangestad, S. W. (1994). Human fluctuating asymmetry and sexual behavior. Psychological Science, 5, 297-302. http://dx.doi .org/10.1111/j.1467-9280.1994.tb00629.x

Thornhill, R., \& Møller, A. P. (1997). Developmental stability, disease and medicine. Biological Reviews of the Cambridge Philosophical Society, 72, 497-548. http://dx.doi.org/10.1017/S0006323197005082

Tomeo, O. B., Ungerleider, L. G., \& Liu, N. (2017). Preference for averageness in faces does not generalize to non-human primates. Frontiers in Behavioral Neuroscience. Advance online publication. http://dx .doi.org/10.3389/fnbeh.2017.00129

Van Duuren, M., Kendell-Scott, L., \& Stark, N. (2003). Early aesthetic choices: Infant preferences for attractive premature infant faces. International Journal of Behavioral Development, 27, 212-219. http://dx.doi .org/10.1080/01650250244000218

Waitt, C., Gerald, M. S., Little, A. C., \& Kraiselburd, E. (2006). Selective attention toward female secondary sexual color in male rhesus macaques. American Journal of Primatology, 68, 738-744. http://dx.doi .org/10.1002/ajp.20264 
Waitt, C., \& Little, A. C. (2006). Preferences for symmetry in conspecific facial shape among Macaca mulatta. International Journal of Primatology, 27, 133-145. http://dx.doi.org/10.1007/s10764-005-9015-y

Waitt, C., Little, A. C., Wolfensohn, S., Honess, P., Brown, A. P., Buchanan-Smith, H. M., \& Perrett, D. I. (2003). Evidence from rhesus macaques suggests that male coloration plays a role in female primate mate choice. Proceedings Biological Sciences, 270(Suppl. 2), S144S146. http://dx.doi.org/10.1098/rsbl.2003.0065

Wallis, G. (2013). Toward a unified model of face and object recognition in the human visual system. Frontiers in Psychology. Advance online publication. http://dx.doi.org/10.3389/fpsyg.2013.00497

Wallis, G., Siebeck, U. E., Swann, K., Blanz, V., \& Bülthoff, H. H. (2008). The prototype effect revisited: Evidence for an abstract feature model of face recognition. Journal of Vision, 8, 20. http://dx.doi.org/10.1167/8.3.20
Zebrowitz, L. A., \& Rhodes, G. (2004). Sensitivity to "bad genes" and the anomalous face overgeneralization effect: Cue validity, cue utilization, and accuracy in judging intelligence and health. Journal of Nonverbal Behavior, 28, 167-185. http://dx.doi.org/10.1023/B:JONB.0000039648 $.30935 .1 \mathrm{~b}$

Received October 10, 2017 Revision received July 9, 2018

Accepted July 16, 2018 